\title{
Protective effect of silk lutein on ultraviolet B-irradiated human keratinocytes
}

\author{
Sutatip Pongcharoen ${ }^{1 *}$, Prateep Warnnissorn ${ }^{1}$, Ongart Leŗtkajornsin², Nanteetip Limpeanchob ${ }^{3}$ and Manote \\ Sutheerawattananonda ${ }^{4}$ \\ ${ }^{1}$ Departments of Medicine \\ 2 Surgery, Faculty of Medicine \\ ${ }^{3}$ Department of Pharmaceutical Practice, Faculty of Pharmaceutical Sciences, Naresuan University, Phitsanulok \\ ${ }^{4}$ School of Food Technology, Institute of Agricultural Technology, Suranaree University of Technology, Nakornrajchasrima, Thailand
}

\begin{abstract}
Carotenoids are efficient antioxidants that are of great importance for human health. Lutein and zeaxanthin are carotinoids present in high concentrations in the human retina which are involved in the photoprotection of the human eye. Lutein may also protect the skin from ultraviolet (UV)-induced damage. The present study investigated the protective effect of lutein extracted from yellow silk cocoons of Bombyx mori on human keratinocytes against UVB irradiation. A human keratinocyte cell line and primary human keratinocytes were used to investigate the UVB protection effects of silk lutein and plant lutein. Silk lutein showed no cytotoxicity to keratinocytes. Treatment with silk lutein prior to UVB irradiation enhanced cell viability and cell proliferation, and reduced cell apoptosis. The protective effects of silk lutein may be superior to those of plant lutein. Silk lutein may have a benefit for protection of keratinocytes against UVB-irradiation.
\end{abstract}

Key terms: Silk lutein, keratinocytes, UV, apoptosis

\section{INTRODUCTION}

Carotenoids play an important role in photosynthetic system, in which they function as light-harvesting pigments in the blue-green spectral region (Polivka and Sundstrom, 2004). Carotenoids including alpha- and beta-carotene, betacryptoxanthin, lutein, and zeaxanthin, found in vegetables and fruits as well as in egg yolk, are known to have anti-oxidant properties that reduce cell damage caused by free radicals (Bailey et al., 2009; Johnson, 2009; Polidori et al., 2009; Maiani et al., 2009; Santocono et al., 2007; Trevithick-Sutton et al., 2006). Carotenoid consumption may also help to decrease the risk of developing malignancies (Chang et al., 2005; Jeong et al., 2009; Pelucchi et al., 2008), associated with decreases in oxidative stress (Thomson et al., 2007; Tamimi et al., 2009) and DNA damage (Santocono et al., 2007; Yong et al., 2009).

Lutein and zeaxanthin have been reported to help in protecting the skin against ultraviolet irradiation-induced damage (Santocono et al., 2006; Roberts and Green, 2009). They reduce photoageing and photocarcinogenesis resulting from UVB irradiation (Astner et al., 2007). A previous study in humans has shown that both consumption and external application of lutein and zeaxanthin can protect the skin from oxidation. In that study, several parameters including surface lipids, hydration, photoprotective activity, elasticity, and lipid peroxidation were assessed (Palombo et al, 2007). The molecular formula of lutein is $\mathrm{C}_{40} \mathrm{H}_{52} \mathrm{O}_{2}$ and its molecular weight is 644 daltons. The lutein molecule has double bonds, forming a more chemically reactive allylic hydroxyl end group than those extra conjugated double bonds found in zeaxanthin (Kopczynski et al., 2005).

The present study investigated the effect of lutein extracted from silk on human keratinocytes in vitro. We hypothesized that silk lutein may protect keratinocytes from UVB irradiation. In addition, the currently available commercial plant lutein, which is an ester form (Harikumar et al., 2008) was also tested. Silk lutein prepared from yellow silk cocoons in this present study was in a protein binding form that was a sericin-lutein complex. Sericin is one of the main protein constituents of yellow silk cocoons. The yellow pigment-binding protein of this silk lutein is similar to the pigmented tissues of the macular lutea in the retina of the eye. It is possible that absorption and transportation of protein-binding lutein within the body may be better than lutein-fatty acids esters. For these reasons, we hypothesized that the protective effect, if any, of silk lutein may be superior to lutein esters extracted from plants.

\section{METHODS}

\section{Silk lutein}

Silk lutein was prepared according to patent pending no. PCT/TH2010/000048. Yellow silk cocoons of Bombyx mori were degummed under high pressure and temperature to remove sericin. Degummed cocoons were extracted with a solvent mixture of hexane, ethyl alcohol, and ethyl acetate. The solution obtained was then partitioned with $10 \% \mathrm{NaCl}$ to remove impurities from the non-aqueous phase to the aqueous phase. The non-aqueous phase was concentrated at ambient temperature and freeze-dried. Silk lutein concentration was quantified by reversed-phase HPLC (Agilent HP 1100 series) using a LiChrospher ${ }^{\circledR} 100$ reversed-phase $C_{18}$ column as stationary and acetonitrile/methanol-ethyl acetate as mobile phases and monitored at $445 \mathrm{~nm}$. The lutein was kept in the dark at $-20{ }^{\circ} \mathrm{C}$ until use. 


\section{Keratinocyte cell line}

Human keratinocyte cell line (CCD 1102 KERTr) (the American Type Culture Collection, University Boulevard, Manassas, VA, USA) was maintained in $100 \mathrm{~mm}^{2}$ sterile Petri dishes in Keratinocyte-serum-free medium (Gibco, NY, USA), containing $1 \%$ antibiotics, $20-30 \mu \mathrm{g} / \mathrm{ml}$ of bovine pituitary extract, $0.1 \%$ $300 \mathrm{mM} \mathrm{CaCl}$, and $200 \mathrm{ng} / \mathrm{ml}$ of recombinant epidermal growth factor. The cells were incubated at $37{ }^{\circ} \mathrm{C}$ and $5 \% \mathrm{CO}_{2}$. Approximately $95 \%$ confluent cultures were passaged every 4-5 days by trypsinization with $0.25 \%$ trypsin-EDTA (Gibco) in phosphate-buffered saline (PBS: Sigma-Aldrich, MO, USA).

\section{Primary human keratinocytes}

Primary human keratinocytes were isolated from foreskins of boys less than 10 years old $(n=5)$ and from an adult skin after an approval from the Ethical Committee on Human Rights Research Involving Human Subjects, Naresuan University. After removal of excess subcutaneous fat and dermis, the skin was cut into small pieces and soaked in $2.5 \mathrm{mg} / \mathrm{ml}$ dispase II (Roche Applied Science, Mannhiem, Germany) at $4{ }^{\circ} \mathrm{C}$ for 48 hours. Epidermal sheets were carefully separated from dermis and immediately trypsinized to obtain single cell suspensions in $0.05 \%$ trypsin-EDTA (Invitrogen, Carlsbad, CA) and neutralized with $10 \%$ fetal calf serum in DMEM (both obtained from Thermo Scientific, Waltham, MA). The trypsinized single cell suspension was cultured in Keratinocyte Serum-Free Medium (Ker SFM; Invitrogen) supplemented with $25 \mu \mathrm{g} / \mathrm{ml}$ bovine pituitary extract, $0.2 \mathrm{ng} / \mathrm{ml}$ epidermal growth factor and $0.4 \mathrm{mM} \mathrm{CaCl}_{2}$, according to Rheinwald et al. (2002). Keratinocytes from the third to the fifth subcultures were used in our study. To demonstrate that almost all of the cultured cells were keratinocytes, the cells were fixed with cold ethanol while vortexing and were then stained with a marker of keratinocyte, anti-pan-cytokeratinFITC antibody (Sigma-Aldrich) according to the manufacturer recommendation. These cultured keratinocytes were shown by FACSCalibur (BD, San Jose, CA) to be stained more than $95 \%$ with this antibody (data not shown).

\section{Lutein administration and UVB irradiation}

Keratinocyte cell lines and human keratinocytes were plated at $2 \times 10^{5}$ cells $/ 60 \mathrm{~mm}^{2}$ culture dishes for 24 hours before the plates were added with silk lutein or commercial lutein, Xanthophyll (Fluka, Sigma-Aldrich). The concentrations of both types of lutein were $0.5,1.5,5$, and $15 \mu \mathrm{M}$ in culture medium. The culture dishes were then incubated for another 24 hours. Then the medium containg lutein was removed by gently pipetting the medium out followed by gentle and thorough washes with PBS. The culture dishes were then supplemented with Earle's Balanced Salt Solution 1X (EBSS) (Gibco) normal complete medium before they were irradiated with UVB using a BS-03 irradiation chamber (Dr. Grobel UVElektronik $\mathrm{GmbH}$, Ettlingen, Germany), ranging from 8 to $32 \mathrm{~mJ} / \mathrm{cm}^{2}$. This range of irradiation was evaluated in our preliminary studies using the same conditions of keratinocyte culture and the same number of passages, which showed that at UVB of $\geq 32 \mathrm{~mJ} / \mathrm{cm}^{2}$ most of the cells were killed (data not shown). For the keratinocyte cell line the UVB doses were 8 , 16,24 , and $32 \mathrm{~mJ} / \mathrm{cm}^{2}$ and the lutein concentrations were 0.5 , $1.5,5$, and $15 \mu \mathrm{M}$. For human keratinocytes the UV doses were
16,24 , and $32 \mathrm{~mJ} / \mathrm{cm}^{2}$ and the lutein concentrations were 1.5, 5, and $15 \mu \mathrm{M}$. After irradiation, the EBSS was gently removed and then Keratinocyte-SFM medium was added.

\section{Cell survival assay}

Trypan blue exclusion as well as MTT assays were carried out in order to determine the effect of lutein on the survival of keratinocytes. The assays were also performed to investigate the viability of keratinocytes which were treated with lutein prior to UBV-irradiation at 8 to $32 \mathrm{~mJ} / \mathrm{cm}^{2}$. Briefly, keratinocytes treated with silk lutein or commercial lutein, hereafter referred to as c-lutein, as above were evaluated for the total number of cells and the number of dead cells using trypan blue exclusion and MTT assays. For the UVB irradiation experiments, lutein treated cells were irradiated with UVB at 8 to $32 \mathrm{~mJ} / \mathrm{cm}^{2}$ before they were cultured for another 24 hours. These cells were then evaluated for the total number of live cells and dead cells by trypan blue exclusion as well as MTT assay. Briefly, for MTT assay keratinocytes were plated into 96-well flat-bottom tissue culture plates at $1.5 \times 10^{4}$ cells/well. After an overnight culture, lutein and c-lutein were added at the same concentrations as above. The cultures were similarly irradiated with UVB and washed as aforementioned. Two hours before the assays were terminated, freshly prepared thiazolyl blue tetrazolium bromide; MTT (Sigma) solution was added at a final concentration of $0.5 \mathrm{mg} / \mathrm{ml}$. At the end of the culture period, the culture plates were flicked off and tapped before $100 \mu \mathrm{l} /$ well of dimethyl sulfoxide (DMSO; Sigma) in ethanol $(1: 1, \mathrm{v} / \mathrm{v})$ was added. The plates were further incubated for 5 minutes and then the absorbance was read at $595 \mathrm{~nm}$ using an iMark Microplate Reader (Bio-Rad, Hercules, CA, USA).

Apoptosis assay

Apoptosis assay using an annexin V-FITC apoptosis detection kit (BD Biosciences, CA, USA) was performed to assess the effect of lutein and c-lutein on the apoptosis of keratinocytes as well as to investigate the effect of cell apoptosis caused by UVB-irradation on lutein- and c-lutein-treated keratinocytes. Briefly, keratinocytes treated with silk lutein or c-lutein as above were analyzed for cell apoptosis. To do this, some culture dishes were trypsinised to stain with annexin V FITC and the remainder was irradiated with UVB at 8 to $32 \mathrm{~mJ} /$ $\mathrm{cm}^{2}$. After irradiation the culture dishes were incubated for an additional 24 hours before they were trypsinised. The trysinised cells were then stained with annexin V-FITC and propidium iodide for 15 minutes before they were analyzed using FACScalibur (Becton Dickinson, CA, USA) with CellQuestPro software (BD).

\section{Cell proliferation assay}

To determine the ability of keratinocytes to proliferate after they had been exposed to lutein and c-lutein as well as to the UBV as in the survival and apoptosis assays, the BrdUincorporation assay was performed. In these experiments the cells were cultured in 96-well flatted-bottom tissue culture plates at $1.5 \times 10^{4}$ cells $/ \mathrm{ml}$. The treated keratinocytes was added with BrdU of the Cell Proliferation ELISA, BrdU colorimetric kit (Roche Applied Science, IN, USA) 18 hours before the assay was terminated. The color products were developed according 
to the manufacturer's instruction and the absorbance was read at $450 \mathrm{~nm}$ using the iMark Microplate Reader (Bio-Rad).

Statistical analysis

Each assay using human keratinocyte cell lines was performed on at least three different occasions. For primary human keratinocytes $(n=6)$, all samples were tested in all different occasions. Statistical differences were analyzed using twotailed Student's t-test and p values of less than 0.05 were considered significant. The data are presented as mean \pm SD.

\section{RESULTS}

Viability of lutein treated keratinocytes and UVB-irradiated keratinocytes

The results from MTT assays showed that keratinocytes treated with lutein and c-lutein had similar viability compared to keratinocytes in culture medium alone. This means that lutein and c-lutein at this range of concentrations were not toxic to the cells (Figure 1A and 1B).

The effect of lutein on the protection of keratinocytes from UV-irradiation was tested. Silk lutein at the concentrations of
5 and $15 \mu \mathrm{M}$ protected the keratinocytes from UVB mediated cell damage, particularly at 16 and $24 \mathrm{~mJ} / \mathrm{cm}^{2}$ of UVB. This was shown by the ability of the keratinocyte cell line to proliferate after irradiation (Figure 2A). However, c-lutein produced no effect on keratinocyte proliferation (Figure 2B). Thus it appeared that prior treatment with silk lutein helped to protect the cells from UVB-induced cell damage. For the primary keratinocytes, silk lutein at a concentration of $15 \mu \mathrm{M}$ helped in protecting from cellular damage, which was seen in the UVB of 24 and $32 \mathrm{~mJ} / \mathrm{cm}^{2}$ (Figure 2C). The c-lutein at a concentration of $15 \mu \mathrm{M}$ also had a protective effect on the primary keratinocytes treated with $32 \mathrm{~mJ} / \mathrm{cm}^{2}$ of UVB (Figure 2D).

\section{Apoptosis of lutein treated keratinocytes and UVB-irradiation}

The results from the annexin- $\mathrm{V}$ assay showed that the keratinocyte cell line treated with silk lutein and c-lutein in the range of concentrations had similarly few cells undergoing necrosis $(1-2 \%)$, early apoptosis $(4-10 \%)$, and late apoptosis (1-3\%) compared to keratinocytes in culture medium alone (Figure $3 \mathrm{~A}$ and $3 \mathrm{~B}$ ). This means that lutein at this range of concentrations had no effect on cell apoptosis.

\section{A keratinocyte cell line}

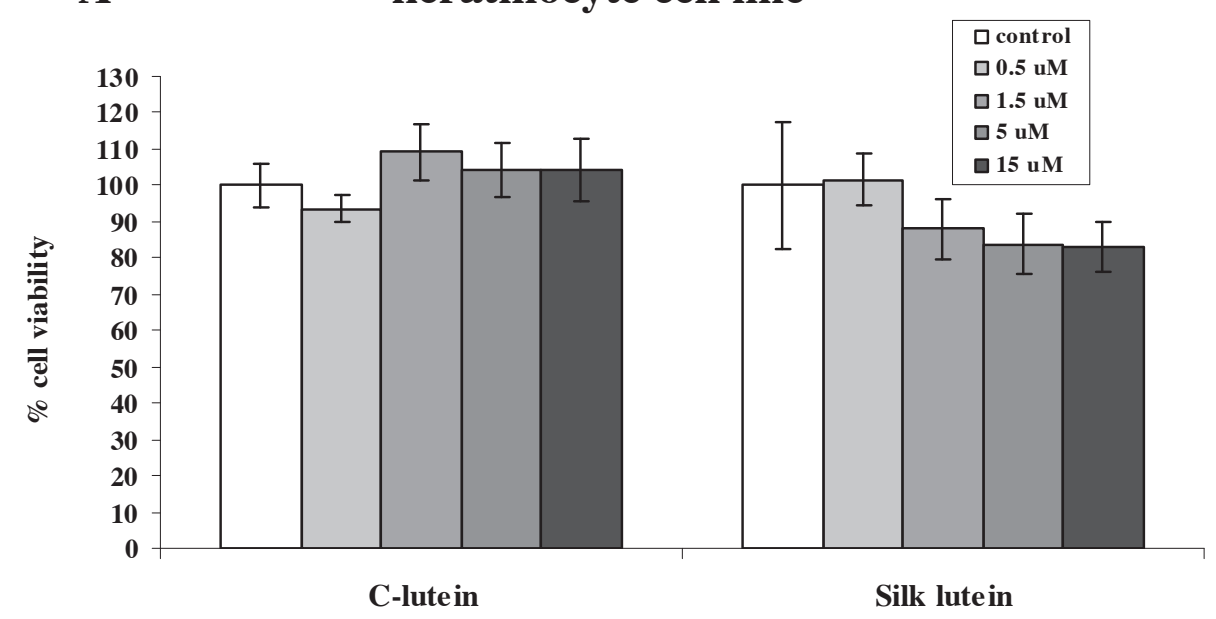

Figure 1 Effect of lutein on the viability of keratinocytes measured by MTT assay. Viability of keratinocyte cell line (A) and primary human keratinocytes (B) treated with c-lutein or silk lutein for 24 hours at concentrations ranging from 0.5 to $15 \mu \mathrm{M}$. Each bar represents the mean percentage of cell viability. Error bars are one standard deviation. 
The keratinocyte cell line treated with either silk lutein or c-lutein at concentrations of 5 and $15 \mu \mathrm{M}$ and then irradiated with $24 \mathrm{~mJ} / \mathrm{cm}^{2}$ of UVB had a significant decrease in the number of cells undergoing early and late apoptosis compared to cells without prior treatment with silk lutein and c-lutein (Figure 4A and 4B). A similar effect was also seen for the primary human keratinocytes (Figure 4C and 4D).

\section{Proliferation of lutein treated and UVB-irradiated keratinocytes}

From the BrdU proliferation assays it was found that the proliferation of both the keratinocyte cell line and primary cells treated with either silk lutein or c-lutein was comparable to that of keratinocytes in culture medium alone (Figure $5 \mathrm{~A}, 5 \mathrm{~B}, 5 \mathrm{C}, 5 \mathrm{D})$. This indicates that lutein at this range
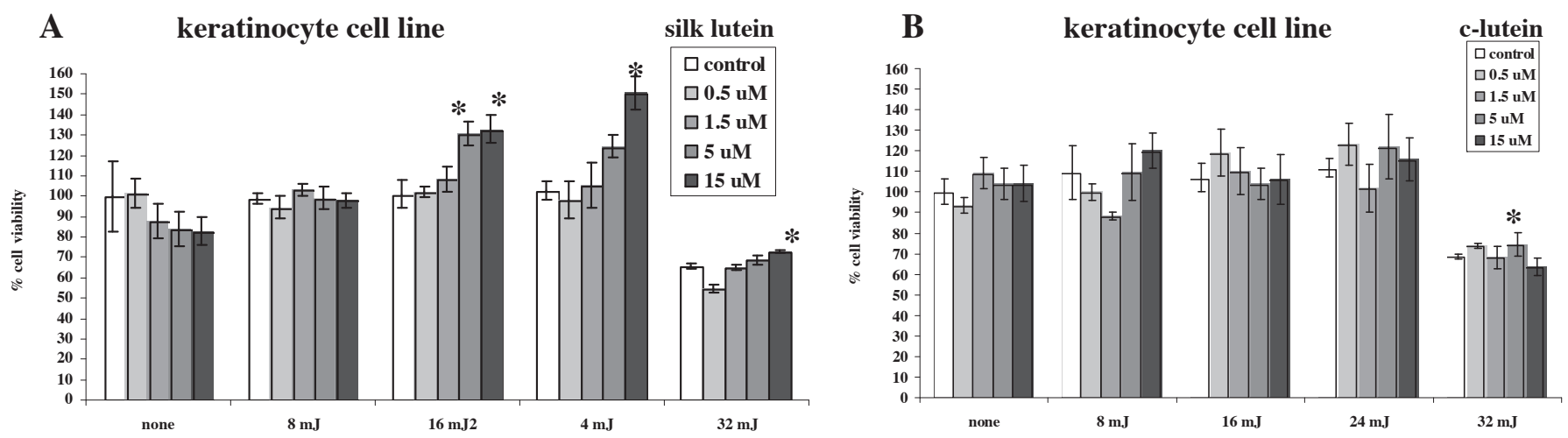

silk lutein
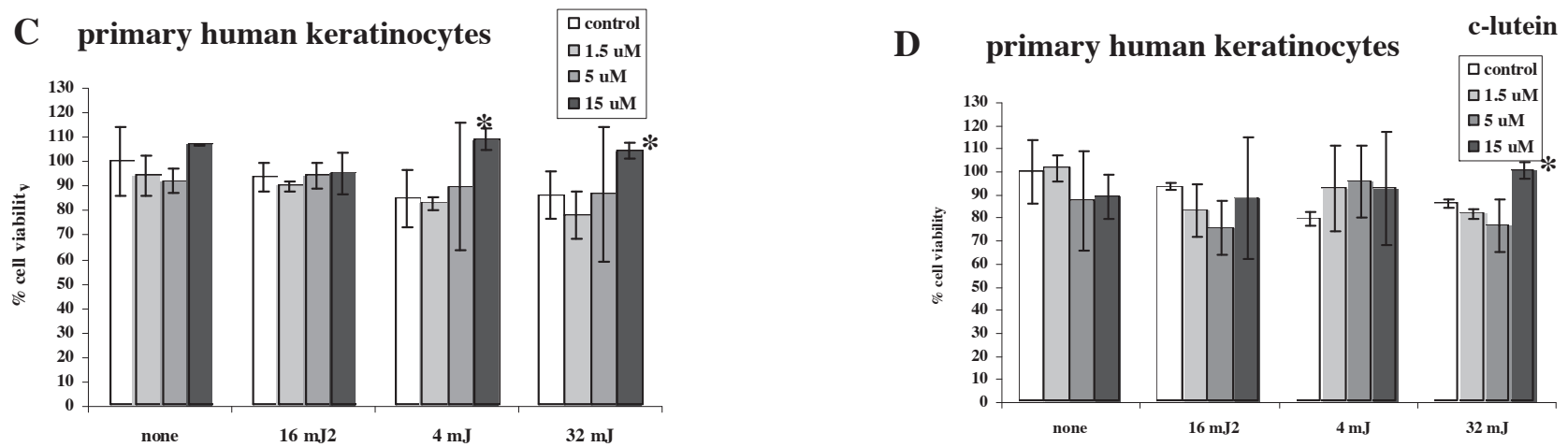

Figure 2 Effect of lutein on the viability of keratinocytes treated with UVB measured by MTT assay. Viability of keratinocyte cell line (A, B) and primary human keratinocytes $(C, D)$ treated with 0.5 to $15 \mu \mathrm{M}$ of silk lutein $(A, C)$ or C-lutein $(B, D)$ for 24 hours prior to irradiation with UVB at various doses ranging from 8 to $32 \mathrm{~mJ} / \mathrm{cm}^{2}$. Each bar represents the percentage of cell viability. Error bars are one standard deviation. *, $\mathrm{p}<0.05$

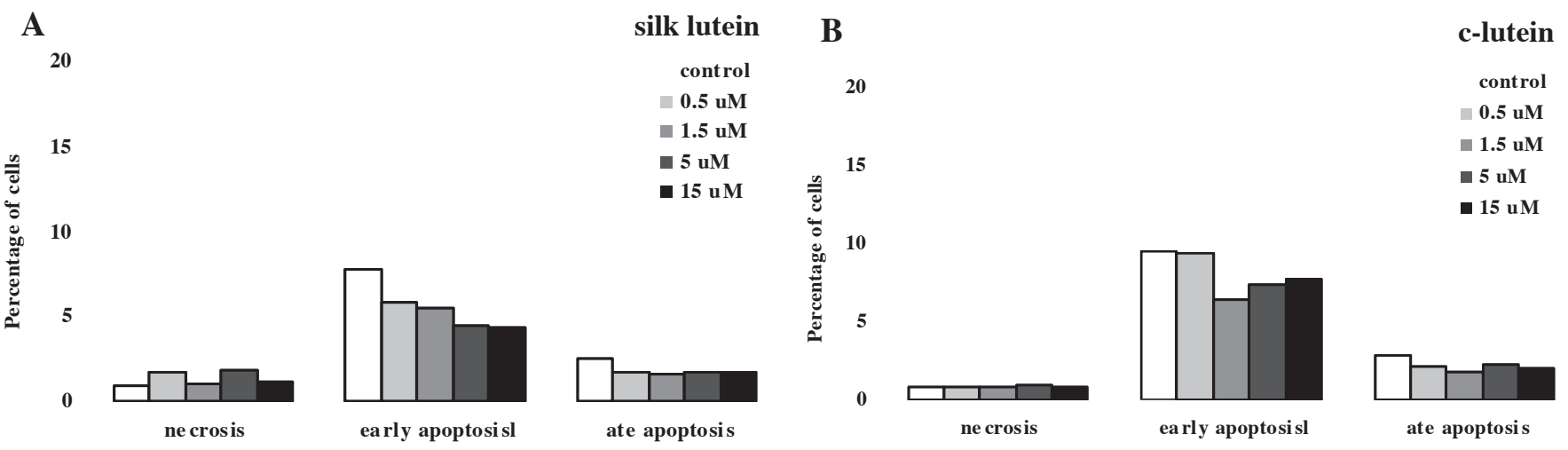

Figure 3 Effect of lutein on the apoptosis of keratinocytes measured by annexin V-FITC assay. Apoptosis of keratinocyte cell line treated with silk lutein (A) or c-lutein (B) for 24 hours at concentrations ranging from 0.5 to $15 \mu \mathrm{M}$. Each bar represents the percentage of cells undergoing apoptosis. Error bars are one standard deviation. 
of concentrations had no effect on the proliferation of keratinocytes.

The keratinocytes treated with silk lutein and c-lutein followed by UVB irradiation from $16 \mathrm{~mJ} / \mathrm{cm}^{2}$ had more cell proliferation, particularly at $15 \mu \mathrm{M}$ lutein, compared to cells without prior treatment with lutein (Figure 5A, 5B, 5C, 5D). Therefore treatment with lutein before UVB irradiation appears to help the proliferation of keratinocytes. The explanation may be that UVB irradiation resulted in some cell death, but 24 hours later the remaining cells continued to proliferate. The controlled keratinocytes without prior treatment with lutein had less proliferation.

\section{DISCUSSION}

The present study demonstrated the effect of silk lutein on human keratinocytes. Primary human keratinocytes were studied along with a keratinocyte cell line. This is because keratinocyte cell lines may have abnormal characteristics including aneuploidy, genetic instability, as well as having heterogeneous cell populations. Thus, they may not represent normal epidermis (van de Sandt et al., 1999). The present study, therefore, used primary human keratinocytes even though this source of normal skin biopsy is limited, particularly from adult normal skin, owing to ethical considerations.

The present findings demonstrated that silk lutein can decrease cell apoptosis caused by UVB-irradiation. It also showed that silk lutein increased the proliferation of keratinocytes that had been treated with UVB. The silk lutein in the present study was in a protein binding form and some of our present results were better than those from c-lutein of plant origins. In the preliminary studies on the doses of UVB only 8 to $32 \mathrm{~mJ} / \mathrm{cm}^{2}$ were tested, because the UVB doses of higher than $32 \mathrm{~mJ} / \mathrm{cm}^{2}$ caused death of most cells both in the absence and presence of lutein and c-lutein. This might be due to the pro-oxidative activity of caroteinoids at high doses of UV (Lutter et al., 2012).

A previous report showed that high dietary intake of lutein and zeaxanthin can reduce the incidence of squamous cell carcinoma of the skin (Heinen et al., 2007). Studies have shown that lutein and zeaxanthin are present in the skin and in vivo studies have claimed their efficacy against ultravioletinduced skin damage (Roberts et al., 2009; Astner et al., 2007). Thus the present findings support this information as silk lutein decreased the number of early and late apoptosis of human keratinocytes exposed to UVB.
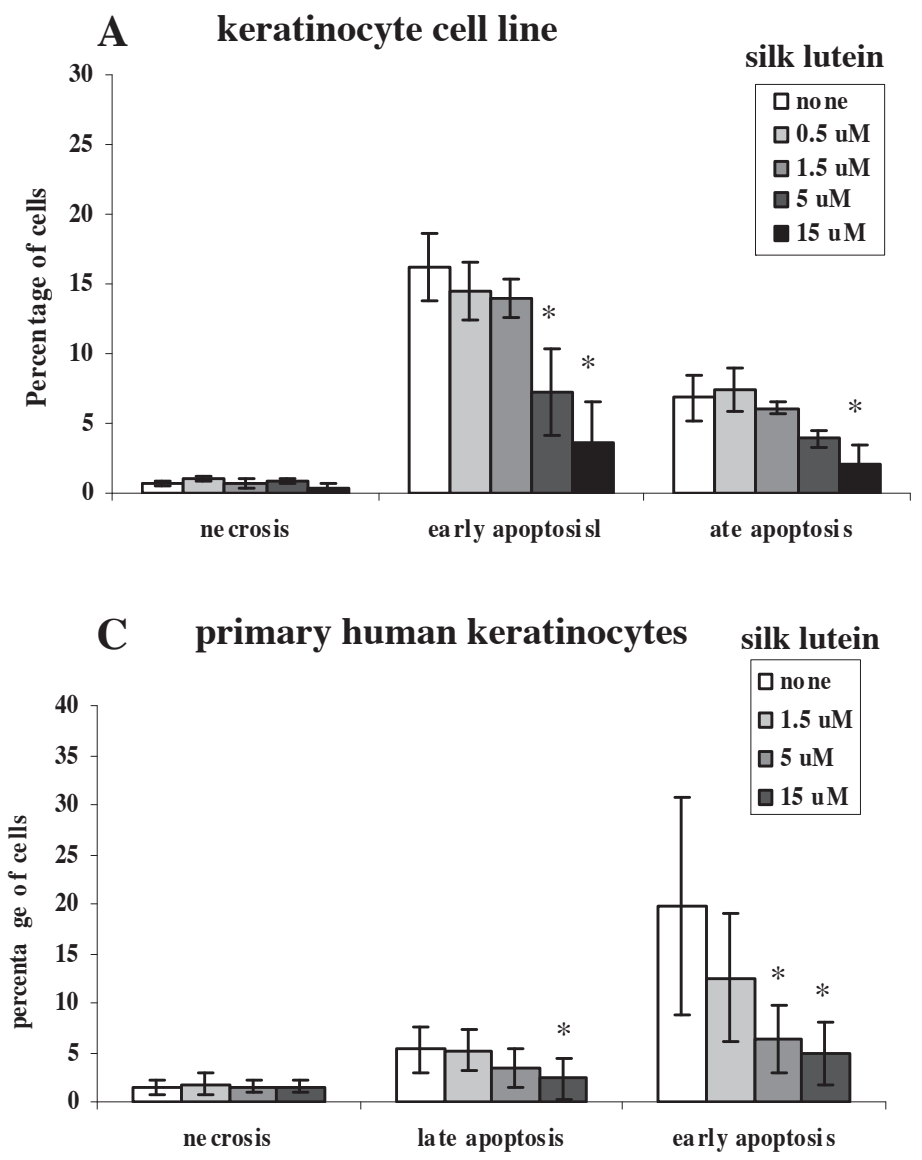

\section{B keratinocyte cell line}

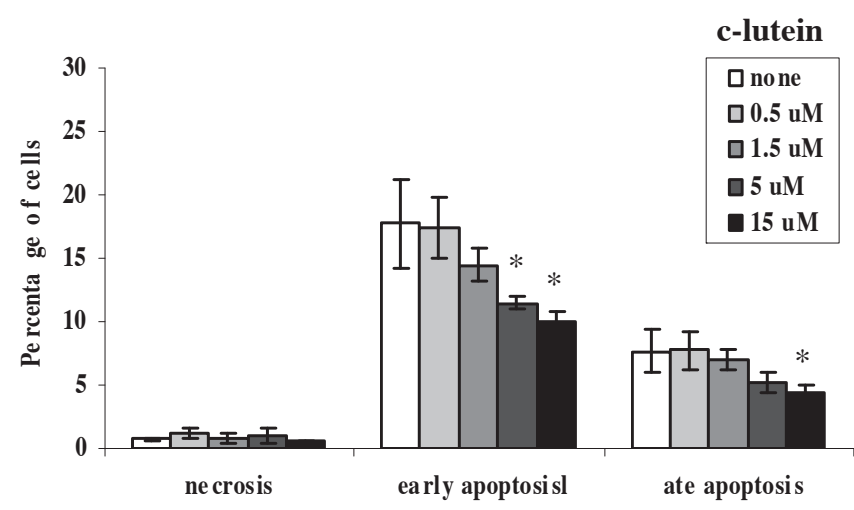

D primary human keratinocytes

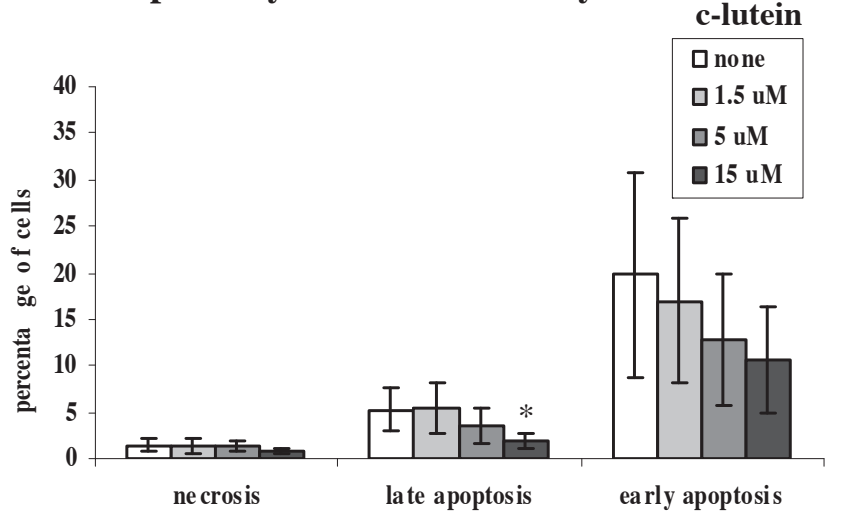

Figure 4 Effect of lutein on the apoptosis of keratinocytes treated with UBV measured by annexin V-FITC assay. Apoptosis of keratinocyte cell line (A, B) and primary human keratinocytes (C, D) treated with 0.5 to $15 \mu \mathrm{M}$ of silk lutein $(A, C)$ or c-lutein (B, D) for 24 hours prior to irradiation with UVB at $24 \mathrm{~mJ} / \mathrm{cm}^{2}$. Each bar represents the percentage of cells undergoing apoptosis. Error bars are one standard deviation. ${ }^{*}, \mathrm{p}<0.05$ 
A

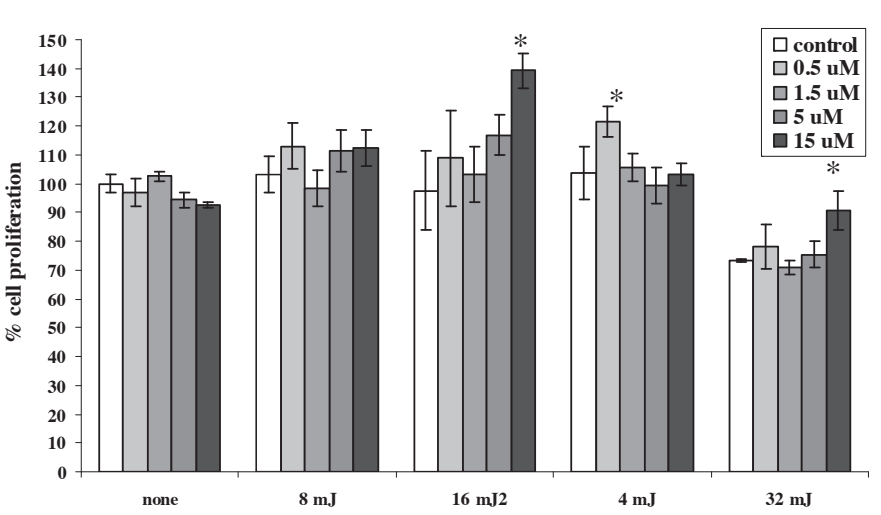

C primary human keratinocytes silk lutein

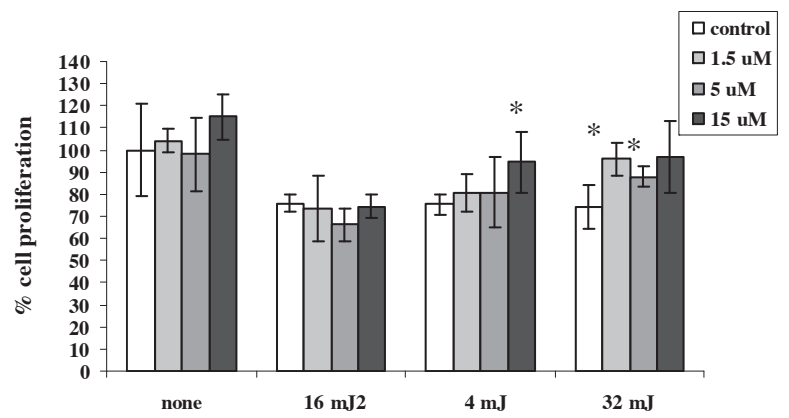

B keratinocyte cell line

c-lutein

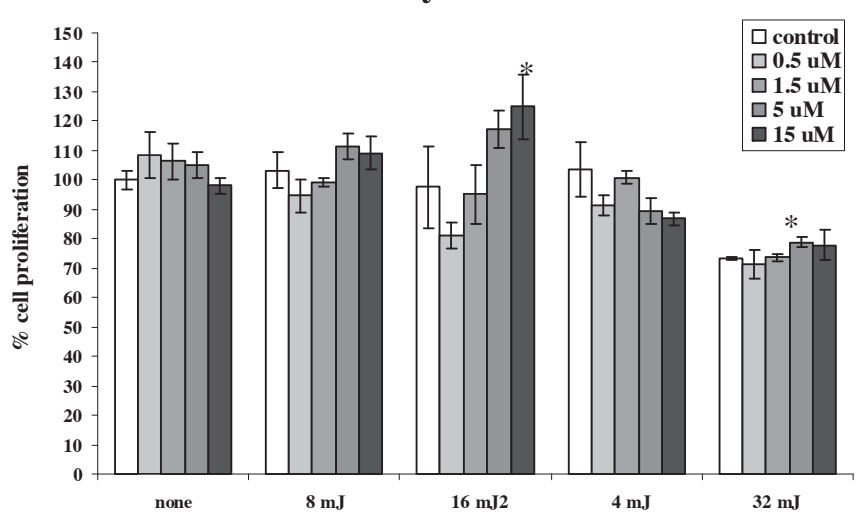

D primary human keratinocytes c-lutein

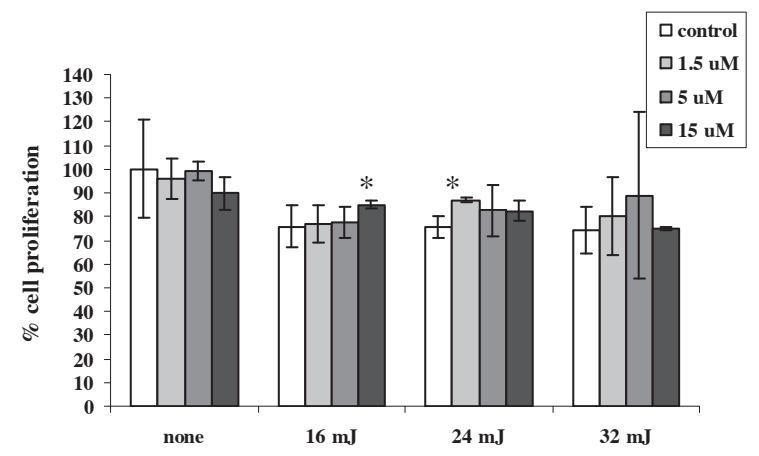

Figure 5 Effect of lutein on the proliferation of keratinocytes measured by BrdU-incorporation assay. Proliferation of keratinocyte cell line $(A, B)$ and primary human keratinocytes $(C, D)$ treated with 0.5 to $15 \mu \mathrm{M}$ of silk lutein $(A, C)$ or c-lutein (B, D) for 24 hours prior to irradiation with UVB at various doses ranging from 8 to $32 \mathrm{~mJ} / \mathrm{cm}^{2}$. Each bar represents the percentage of cell proliferation. Error bars are one standard deviation. ${ }^{*}, \mathrm{p}<0.05$

Although the number of keratinocytes evaluated by BrdU proliferation assay was found to be increased when they were treated with lutein prior to irradiation at $16-24 \mathrm{~mJ} / \mathrm{cm}^{2}$ of UVB, keratinocytes irradiated with other doses of UVB and nonirradiated keratinocytes had similar numbers of cells compared to cells that had not been treated with lutein. This could imply that lutein alone at the range of concentrations used did not stimulate keratinocyte proliferation. However, when the keratinocytes were irradiated with UVB, a number of cells died and the remaining cells continued to proliferate. Silk lutein at a range of concentrations used in this present study provides a protective effect for keratinocytes against UVB-induced damage. Therefore, silk lutein may have a significant benefit in term of skin protection against UVB-irradiation.

\section{ACKNOWLEDGEMENTS}

This work was supported by the Agriculture Research Development Agency (Public Organization), Thailand. The authors thank Miss Kwansuda Supalap and Miss Sanchawan Supalap for technical assistance.

\section{REFERENCES}

ASTNER S, WU A, CHEN J, PHILIPS N, RIUS-DIAZ F, PARRADO C, MIHM MC, GOUKASSIAN DA, PATHAK MA, GONZALEZ S
(2007) Dietary lutein/zeaxanthin partially reduces photoaging and photocarcinogenesis in chronically UVB-irradiated Skh-1 hairless mice. Skin Pharmacol Physiol 20:283-291.

BAILEY RL, MILLER PE, MITCHELL DC, HARTMAN TJ, LAWRENCE FR, SEMPOS CT, SMICIKLAS-WRIGHT H (2009) Dietary screening tool identifies nutritional risk in older adults. Am J Clin Nutr 90:177-183.

CHANG S, ERDMAN SWJR, CLINTON SK, VADIVELOO M, STROM SS, YAMAMURA Y, DUPHORNE CM, SPITZ MR, AMOS AI, CONTOIS JH, GU X, BABAIAN RJ, SCARDINO PT, HURSTING SD (2005) Relationship between plasma carotenoids and prostate cancer. Nutr Cancer 53:127-134.

HARIKUMAR KB, NIMITA CV, PREETHI CK, KUTTAN R, SHANKARANARAYANA ML, DESHPANDE J (2008) Toxicity profile of lutein and lutein ester isolated from marigold flowers (Tagetes erecta). Int J Toxicol 27:1-9.

HEINEN MM, HUGHES MC, IBIEBELE TI, MARKS GC, GREEN AC, VAN DER POLS JC (2007) Intake of antioxidant nutrients and the risk of skin cancer. Eur J Cancer 43:2707-2716.

JEONG NH, SONG ES, LEE JM, LEE KB, KIM MK, YUN YM, LEE JK, SON SK, LEE JP, KIM JH, HUR SY, KWON YI (2009) Preoperative levels of plasma micronutrients are related to endometrial cancer risk. Acta Obstet Gynecol Scand 88:434-439.

JOHNSON JD (2009) Do carotenoids serve as transmembrane radical channels?. Free Radic Biol Med 47:321-323.

KOPCZYNSKI M, LENZER T, OUM K, SEEHUSEN J, SEIDEL MT, USHAKOV VG (2005) Ultrafast transient lens spectroscopy of various $\mathrm{C}_{40}$ carotenoids: lycopene, $\beta$-carotene, $\left(3 R, 3^{\prime} R\right)$-zeaxanthin, $\left(3 R, 3^{\prime} R, 6^{\prime} R\right)$ lutein, echinenone, canthaxanthin, and astaxanthin. Phys Chem Chem Phys 7:2793-2803.

LUTTER K, DE SPIRT S, KOCK S, KRONCKE KD, MARTIN HD, WAGENER T, STAHL W (2010) 3,3,-Dihydroxyisorenieratene prevents UV-induced 
formation of reactive oxygen species and the release of protein-bound zinc ions in human skin fibroblast. Mol Nutr Food Res 54:285-291.

MAIANI G, CASTON MJ, CATASTA G, TOTI E, CAMBRODON IG, BYSTED A, GRANADO-LORENCIO F, OLMEDILLA-ALONSO B, KNUTHSEN $\mathrm{P}$, VALOTI M, BOHM V, MAYER-MIEBACH E, BEHSNILIAN D, SCHLEMMER U (2009) Carotenoids: actual knowledge on food sources, intakes, stability and bioavailability and their protective role in humans. Mol Nutr Food Res 53 Suppl 2:S194-218.

PALOMBO P, FABRIZI G, RUOCCO V, RUOCCO E, FLUHR J, ROBERTS R, MORGANTI P (2007) Beneficial long-term effects of combined oral/ topical antioxidant treatment with the carotenoids lutein and zeaxanthin on human skin: a double-blind, placebo-controlled study. Skin Pharmacol Physiol 20:199-210.

PELUCCHI C, DAL MASO L, MONTELLA M, PARPINEL M, NEGRI E, TALAMINI R, GIUDICE A, FRANCESCHI S, LA VECCHIA C (2008) Dietary intake of carotenoids and retinol and endometrial cancer risk in an Italian case-control study. Cancer Causes Control 19:1209-1215.

POLIDORI MC, CARRILLO JC, VERDE PE, SIES H, SIEGRIST J, STAHL W (2009) Plasma micronutrient status is improved after a 3-month dietary intervention with 5 daily portions of fruits and vegetables: implications for optimal antioxidant levels. Nutr J 8:10.

POLIVKA T, SUNDSTROM V (2004) Ultrafast dynamics of carotenoid excited states-from solution to natural artificial systems. Chem Rev 104:2021-2071.

ROBERTS RL, GREEN J, LEWIS B (2009) Lutein and zeaxanthin in eye and skin health. Clin Dermatol 27:195-201.

SANTOCONO M, ZURRIA M, BERRETTINI M, FEDELI D, FALCIONI G (2006) Influence of astaxanthin, zeaxanthin and lutein on DNA damage and repair in UVA-irradiated cells. J Photochem Photobiol B 85:205-215.
SANTOCONO M, ZURRIA M, BERRETTINI M, FEDELI D, FALCIONI G (2007) Lutein, zeaxanthin and astaxanthin protect against DNA damage in SK-N-SH human neuroblastoma cells induced by reactive nitrogen species. J Photochem Photobiol B 88:1-10.

TAMIMI RM, COLDITZ GA, HANKINSON SE (2009) Circulating carotenoids, mammographic density, and subsequent risk of breast cancer. Cancer Res 69:9323-9329.

THOMSON CA, STENDELL-HOLLIS NR, ROCK CL, CUSSLER EC, FLATT SW, PIERCE JP (2007) Plasma and dietary carotenoids are associated with reduced oxidative stress in women previously treated for breast cancer. Cancer Epidemiol Biomarkers Prev 16:2008-2015.

TREVITHICK-SUTTON CC, FOOTE CS, COLLINS M, TREVITHICK JR (2006) The retinal carotenoids zeaxanthin and lutein scavenge superoxide and hydroxyl radicals: a chemiluminescence and ESR study. Mol Vis 12:1127-1135.

VAN DE SANDT J, ROGUET R, COHEN C, ESDAILE D, PONEC M, CORSINI E, BARKER C, FUSENIG N, LIEBSCH M, BENFORD D, DE BRUGEROLLE DE FRAISSINETTE A, FARTASCH M. (1999) The use of human keratinocytes and human skin models for predicting skin irritation. In: The report and recommendations of ECVAM Workshop 38. Available at: http://ecvam.jrc.it/publication/WorkshopReport38.pdf. Accessed on 6 Feb 2012. ATLA 27:723-743.

YONG LC, PETERSEN MR, SIGURDSON AJ, SAMPSON LA, WARD EM (2009) High dietary antioxidant intakes are associated with decreased chromosome translocation frequency in airline pilots. Am J Clin Nutr 90:1402-1410. 
